\title{
MONITORAMENTO ORBITAL DA EXPANSÃO URBANA NA CIDADE DE ANÁPOLIS- 1997/2000
}

\section{Rafael Sanzio Araújo dos Anjos Juvair Fernandes de Freitas}

p. $43-57$

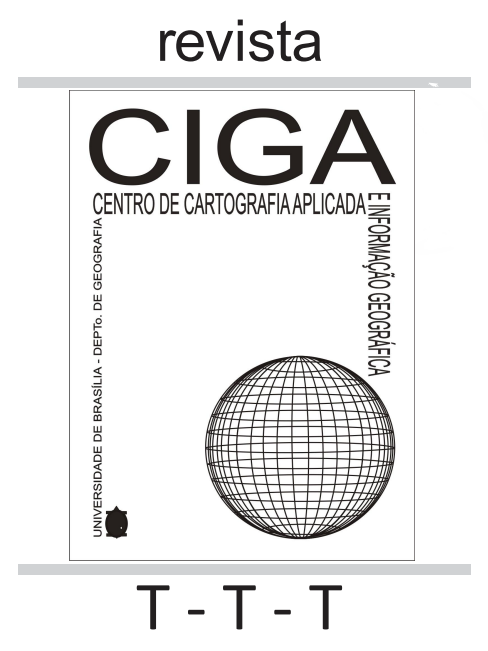

Revista Eletrônica: Tempo-Técnica-Tenitório, V.1, N.1 (2010), 43:57 ISSN: $2177-4366$

DOI: https:// doi.org/10.26512/ ciga.v1i1.15881
Como citar este ar tigo:

FREITAS. F. , Rafael Sanzio Araújo dos Anjos , MONITORAMENTO ORBITAL DA EXPANSÃO URBANA NA CIDADE DE ANÁPOLIS$1997 / 2000$

Revista Eletrônica: Tempo - Técnica - Território, v.1, n.1 (2010), p. 43:57

ISSN: 2177-4366.

DOI: https://doi.org/10.26512/ciga.v1i1.15881

Disponível em:

http://inseer.ibict.br/ciga/index.php/ciga/article/viewFile/288/207

Este obra está licenciado com uma Licença Crea tive Commons Atribuição-NãoComer cial 4.0 Inter nacional. 


\title{
MONITORAMENTO ORBITAL DA EXPANSÃO URBANA NA CIDADE DE ANÁPOLIS - $1997 / 2000$
}

\author{
Juvair Fernandes de Freitas \\ Mestrado em Geografia \\ Universidade de Brasília, UNB, Brasil.
}

\begin{abstract}
Rafael Sanzio Araújo dos Anjos
Geógrafo, Doutor em Informações Espaciais (POLIUSP-BR/IRD-FR), Pós-Doutoramento em Cartografia Étnica (MRAC-BE). Prof. Associado do Depto. de Geografia da UnB. E-mail:

cartografia@unb.br
\end{abstract}

\begin{abstract}
Resumo: o objetivo do artigo é apresentar ao público interessado em estudos sobre as cidades, uma avaliação tópica do processo de expansão urbana na cidade de Anápolis recente, utilizando imagens orbitais, como ferramenta capaz de identificar os principais efeitos desta expansão que traduzirá na segregação e segmentação urbana da cidade. Utilizaremos duas imagens recentes de 1997 e 2000, que associada à carta topográfica disponível datada de 1971, nos oferecerá uma leitura sintética da produção do espaço urbano da mencionada cidade.
\end{abstract}

\begin{abstract}
: the purpose of this article is to present to the public interested in research about cities, a topic evaluation of the process of urban expansion in the recent city of Annapolis, using orbital images, like a tool that is able to identify the main effects of the expansion that will translate in the segregation and in the urban segmentation of the city. We will use two recent images of 1997 and 2000 that, associated with the available topographic map dated 1971, will provide for us a synthetic reading of the production of the urban space of the mentioned city.
\end{abstract}

\section{INTRODUÇÃO}

A literatura sobre temas acerca das cidades brasileiras tem ganhado notoriedade nos últimos anos, principalmente por causa do grande impacto que o processo de migração campo cidade, ocorrido no passado, legou como herança na atualidade. 
$\mathrm{Na}$ geografia brasileira os estudos urbanos tiveram grande repercussão na década de 60 com estudos tópicos, sobretudo no IBGE. Porém no período atual, a análise moderna sobre as cidades teve seu grande marco em 1973, com Harvey, quando publicou o livro Social Justice and the City, apud VASCOCELOS: 358, influenciadno os autores brasileiros que passaram a produzir trabalhos sobre o tema e continuam até os dias atuais cujo cientistas estão quase todos atuando.

Cada vez mais, se intensifica a contradição dentro da sociedade moderna principalmente, em função da reestruturação produtiva, que vivenciamos hoje, em que os problemas da falta de emprego, grande processo de favelização da população nas grandes cidades e precarização da qualidade de vida urbana, contribuem decisivamente para um olhar sobre o urbano com vistas a solucionar os problemas que afetam toda a sociedade.

Consideramos que a análise dos impactos produzidos pela reestruturação produtiva no espaço urbano é um tema recente no campo da discussão teórica. A preocupação em compreender como as cidades estão se reestruturando na escala intra-urbana, sugere uma visão interdisciplinar, para a compreensão do fenômeno. Todavia, para as cidades médias, ainda carece de um diagnóstico e identificação de como elas estão se comportando dentro deste processo.

A cidade de Anápolis, nosso espaço de pesquisa, ao longo do tempo firmou-se como um centro urbano de importância regional que experimenta um grande vulto do seu crescimento urbano, sobretudo nas bordas da cidade. Este fenômeno, está relacionado com sua funcionalidade no contexto regional. Pelo seu desenvolvimento das atividades econômicas, principalmente o comercio atacadista e a industria. Atividades que atraem populações e provocam um crescimento acelerado em seu espaço urbano.

\section{Análise das imagens digitalizadas}

O mapa abaixo Fig.1 elaborado a partir da carta topográfica da Cidade DSG,1971, nos dá uma visão do perímetro urbano da cidade de Anápolis no início da década de 1970. Observa fig.6 o início da periferização urbana da cidade, algumas áreas amarelas não contínua. Este processo culminou-se com a reserva de estoques de lotes nas áreas intermediárias, que podemos verificar através dos mapas de 1997 e 2000 fig. 2 e 3. 
Através da imagem de Satélite Landsat 1997, pudemos obter informações sensoriais sobre a mancha urbana da cidade de 1997. Constatamos que a mesma obedeceu a um critério de expansão seguindo, sobretudo a saída Norte, Trevo de Brasília e Trevo de Goiânia, sendo que a intensidade maior ocorreu para a Saída Norte. Isto se deve as condições topográficas favoráveis, pois a saída para Goiânia apresenta se bastante acidentadas, em sua grande maioria imprópria para assentamento urbano. Também foi registrado, ( mapa 2 e 3, imagem digitalizada), que a expansão Urbana estende-se fora do limite do município, dando a entender na primeira vista erro no tratamento das informações geográficas. Entretanto, tal situação realmente ocorreu de fato, adentrando no município de Gameleira, recém desmembrado de Silvânia na década de 90. A área observada, situada ao sul do perímetro urbano, constitui uma área que não recebe infra-estrutura de equipamento e serviços básicos a população da prefeitura de Anápolis de forma satisfatória, isto se deve porque não pertence ao Município de Anápolis e também os serviços urbanos que deveriam receber da cidade de Gameleira, não são prestados, sendo reconhecida como área rural, segundo a legislação do Município, apesar de constituir de fato em área urbana, há dificuldade de prover os equipamentos básicos à população pela Prefeitura de Gameleira por impedimento da lei do uso do solo vigente, constituindo se, portanto uma população segregada por motivações jurisdicionais (veja no mapa 2)

A comparação da Área de Expansão Urbana de Anápolis de 1997 para a área de expansão urbana de 2000, observada nos mapas 2 e 3, deixa claro que está ocorrendo um aumento considerável de manchas urbanas nestas localidades mencionadas apesar do espaço curto de tempo de análise, apenas 3 anos, mas já se observa uma pressão sobre a área rural especialmente nesta localidade, que vai além dos limites territoriais da jurisdição de Anápolis, caracterizada pela precarização da qualidade de vida da população.

Além disso, podemos inferir que a expansão da disseminação dos domicílios urbanos em Anápolis ocorre, sobretudo nos trevos que representam a saída para Goiânia, Brasília e saída Norte em direção a Corumbá e ao Norte do Estado seguindo a $\mathrm{Br}$ 153, estando, portanto, submetido a influencia da centralidade das duas metrópoles Goiânia e Brasília, e na Região Norte por causa do menor valor agregado ao imóvel, como a incorporação de bens e serviços distribuídos à população, ainda é precária, não há uma valorização significativa dos espaços vazios, fazendo ressalva à obra de duplicação da rodovia Federal BR153 (Belém Brasília) em curso. 


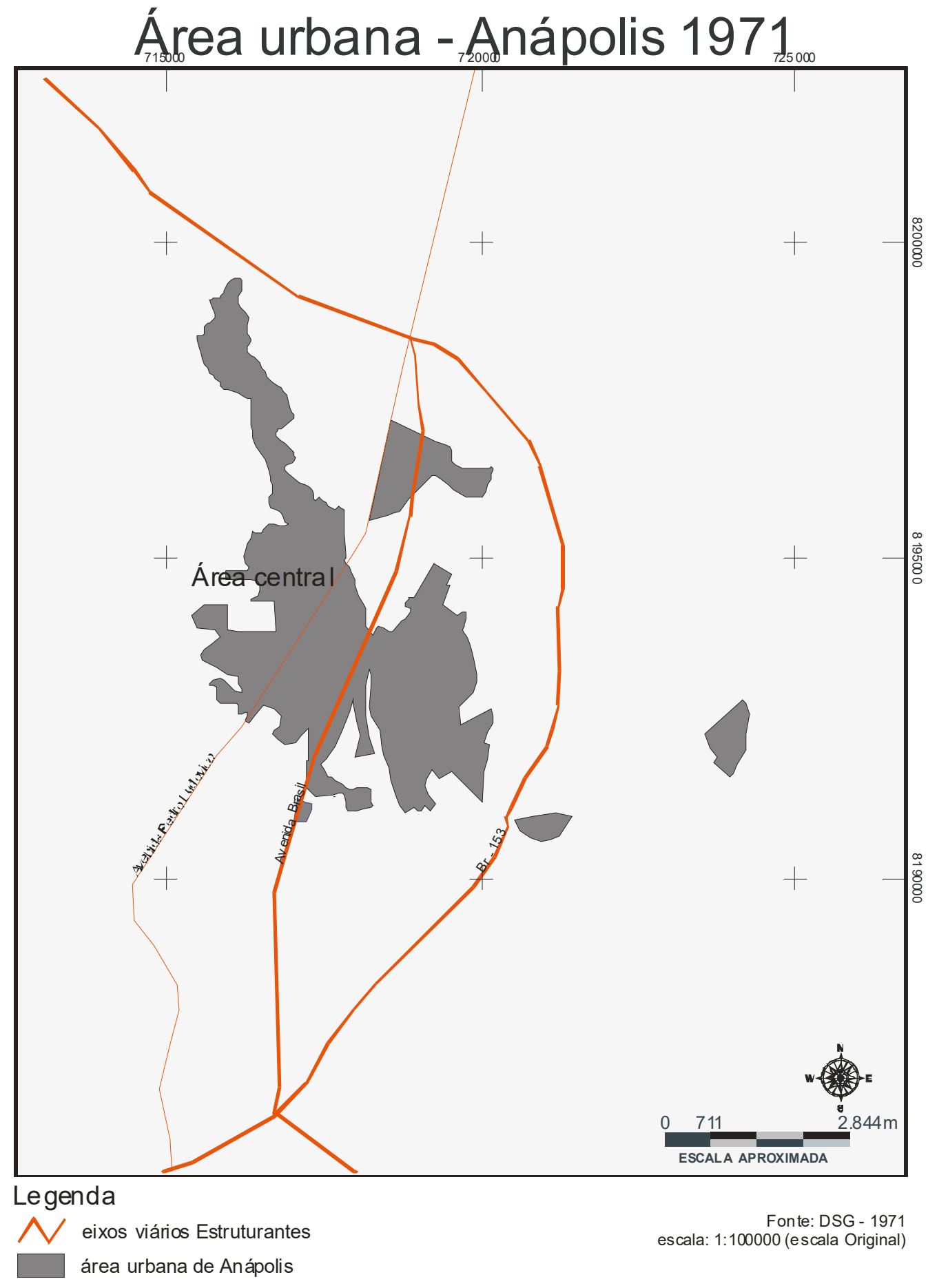

Universid ade de Basilia / Pós Graduação em Ge ografia Urbana eRegiona / Mestrado em Geografia. Alu no: Juv air Fernardes deFreitas / Orien tador: Dr. Rafa elSanzi o A. Dos Anjos. "A Expansão U rbana e a Segre gação Sócio-Es pacial em Anápo lis - Goi ás"

Fig.1 


\section{Área urbana - Anápolis - 1997}

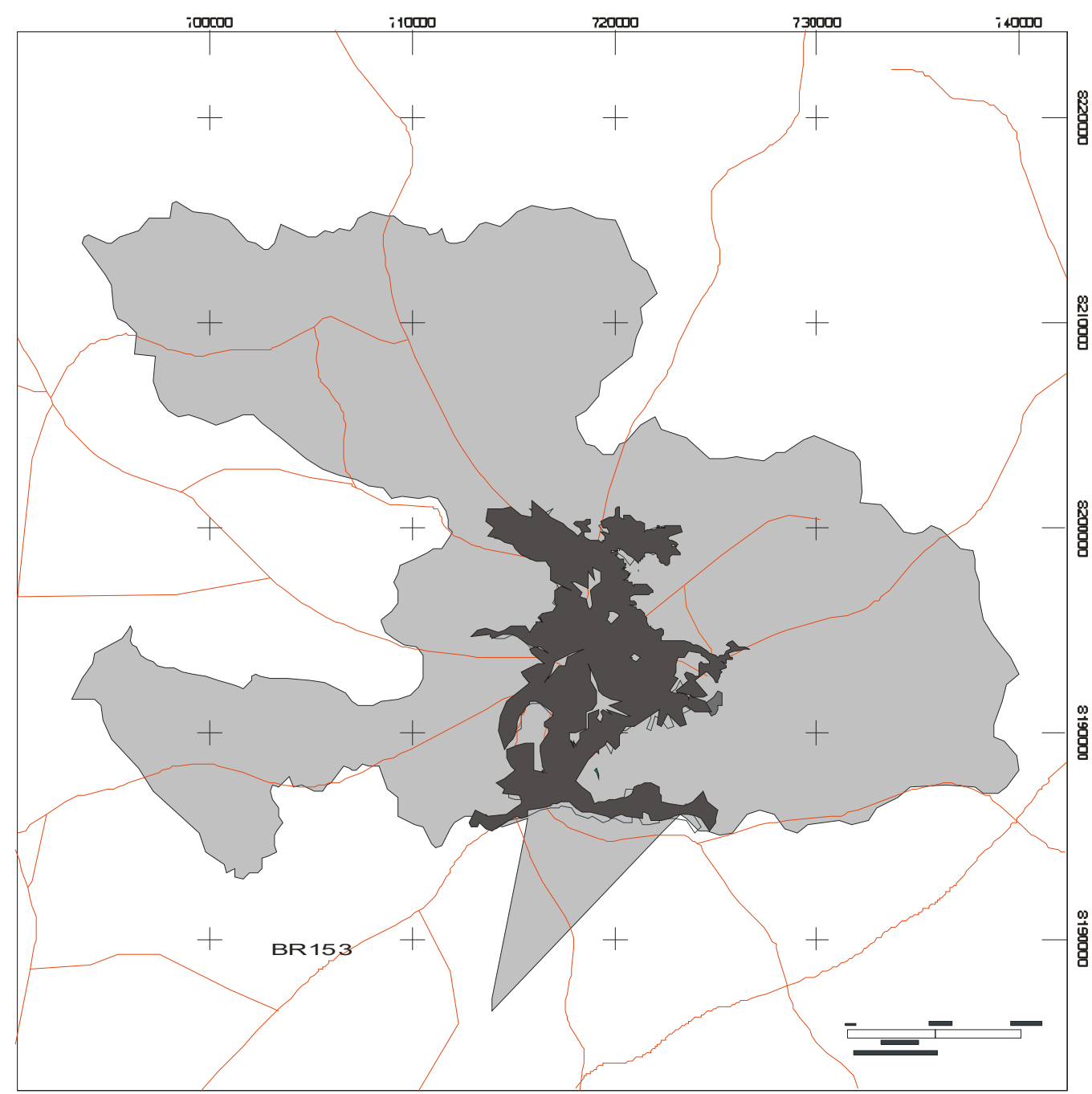

\section{Leçenda}

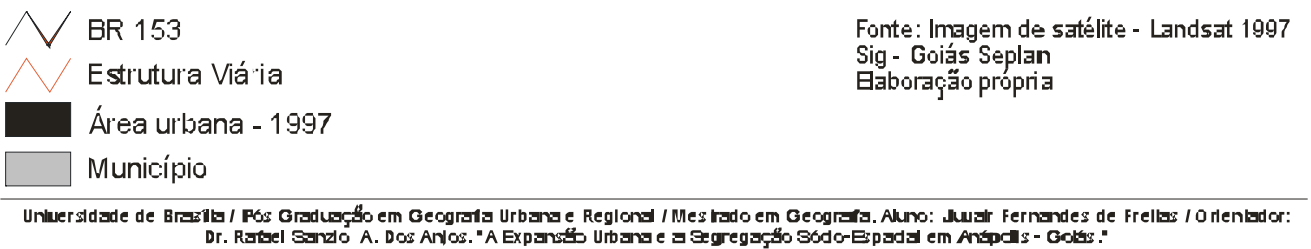

Fig.2

O mapa abaixo, (Fig.3) nos oferece uma visão do crescimento urbano em direção a região oeste da cidade. A área em questão corresponde à saída para a cidade de Nerópolis, e não apresenta um crescimento urbano significativo.Tal fato se deve principalmente as condições desfavoráveis da área para a ocupação urbana, apresentando se muito acidentado, conforme registro na imagem de satélite Landsat/2000 e atestado por trabalho de campo na área. Geralmente, a ocupação urbana nesta área se 
dá de forma irregular, denominada de subnormais correspondendo às invasões de áreas para habitação dentro do contexto urbano de Anápolis

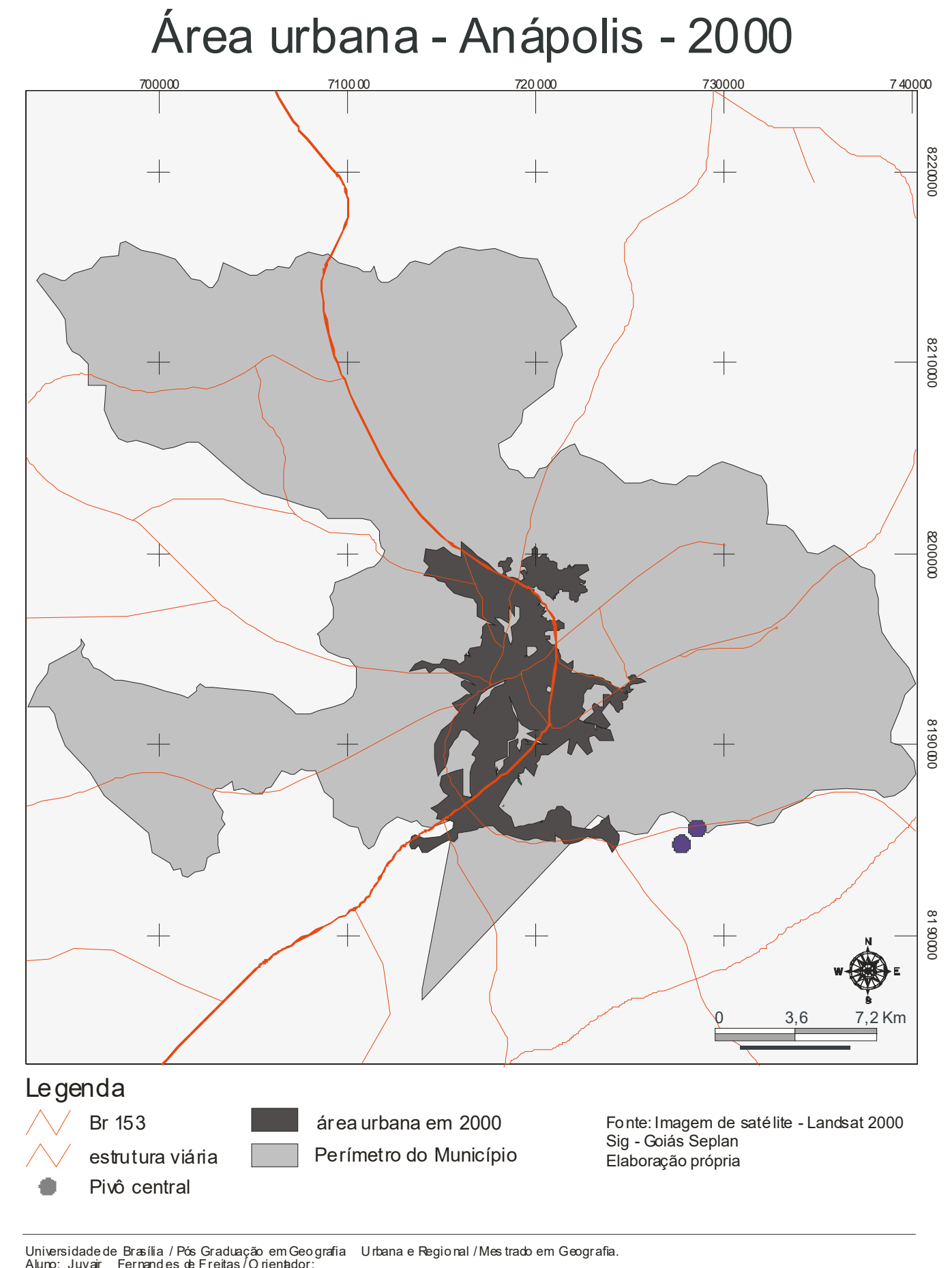

Fig.3 Dr. Rafa el Sanzi o A. Dos Anjos. "A Expan sãoU rb anae a Segreg ação Só cio-Espacial em Anápolis - Goiás." 
No mapa abaixo Fig.4 podemos observar através da sobreposição da imagem digitalizada de 2000 sobre a imagem de 1997, um claro avanço da área urbanizada. As cores correspondentes ao perímetro azul referem-se à expansão e disseminação urbanas da cidade no período de 2000 , e a amarela a área urbanizada em 1997. Verifica-se a partir desta sobreposição um processo intenso de urbanização da cidade, e em muitos lugares ocorrem em área de risco, com declividade bastante acentuada, contribuindo assim para um impacto no ambiente urbano com possíveis precarizações da qualidade de vida da população, haja vista, que é comum a ocupação em sua grande maioria por populações carentes, sendo, portanto disputado por uma camada da população mais pobre para a sua residência, dado ao fato de não possuírem renda o suficiente para aquisição de lotes em outras áreas. Este fato revela de certa forma um fenômeno da segregação sócio-espacial contida nas cidades, uma vez que as populações de baixa renda vão sendo "empurradas" automaticamente para as áreas menos valorizadas, criando problemas para toda a comunidade, uma vez que este processo transforma as populações precarizadas como agentes poluidores de mananciais hídricos importantes a toda comunidade. 


\section{Área de expansão urbana Anápolis - 1997/2000}

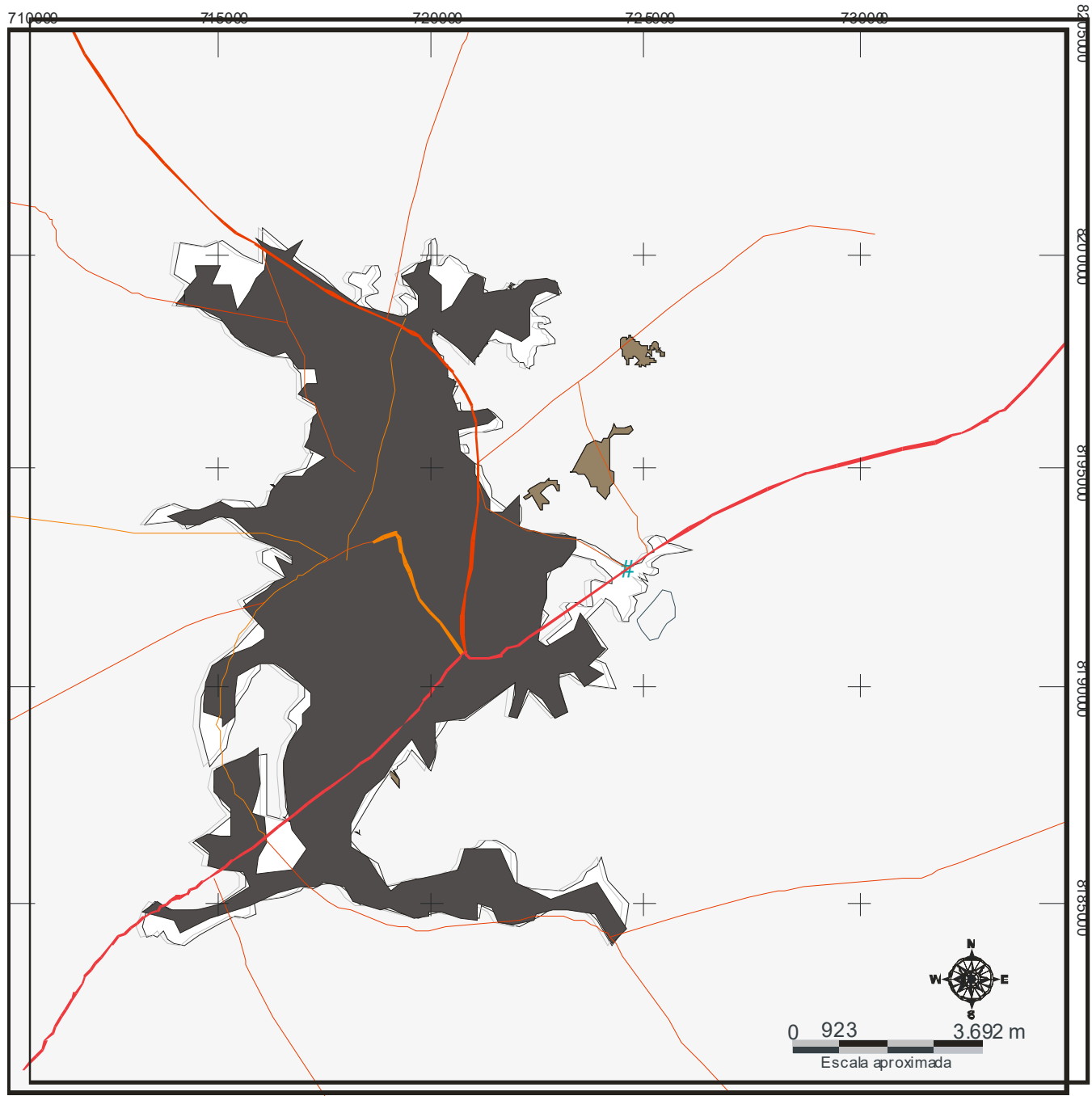

Legenda

\# Trevo viário

Estrutura Viária

N BR 153

área urbana 1997

cres cimento urbano de 1997 à 2000

Fonte: Imagens de Satélite - Landsat 2000 e 1997 Elaboração própria

Fig. 4

Universidade de Brasília / Pós Graduação em Geografia Urbana e Regional / Mestrado em Geografia. Aluno: Juvair Femandes de Freitas / Orientador: Dr. Rafael Sanzio A. Dos Anjos. "A Expansão Urbana e a Segregação Socio-Espacial em Anápolis - Goiás." 
A área de expansão e de disseminação urbana de Anápolis para o ano 2000 observado através da imagem de Satélite- Landsat- 2000, sobreposto às informações multitemporal do crescimento urbano da cidade com seus eixos estruturantes, nos dá uma visão mais detalhada dos vetores de expansão urbana nesta cidade, constatando a afirmativa preconizada no início do trabalho que a expansão urbana de Anápolis ocorria de forma mais intensa em direção aos trevos rodoviários ${ }^{1}$. Isto se explica, sobretudo porque estaria influenciada por duas variáveis: de um lado a centralidade das duas metrópoles, Goiânia e Brasília e por outro lado, em função das condições topográficas das localidades ao norte de Anápolis permitir a ampliação do sítio urbano, e acresce a isto os baixos valores imobiliários verificados nesta área da cidade.

A imagem representa uma síntese, do uso da terra, perímetro urbano de Anápolis de 1997 e 2000, o polígono amarelo refere-se a área de expansão urbana, datada do ano 2000 seguido pelos seus eixos estruturantes onde foram constatado os vetores da expansão urbana da cidade. A análise da expansão e disseminação urbana da cidade oferece mais uma ferramenta para o uso dos planejadores urbanos, sobretudo gestores públicos que buscam soluções aos problemas inerentes à expansão urbana sem controle, constituindo assim o lado perverso da gestão pública municipal, pois onera toda a prestação de serviços à população, uma vez que tais serviços deveriam estar onde há domicílios. Quanto mais se intensifica o crescimento da cidade maior são as demandas por equipamentos urbanos necessários a uma melhor qualidade de vida das pessoas. Neste sentido, o bom senso recomenda que a expansão urbana deveria ser feita onde já existem as estruturas de prestações de serviços à população, pois assim permitiria a formação de cidades mais solidárias, funcionais e com melhor qualidade de vida. Desonerando a gestão pública, evitando fazer obras em espaços vazios, que surgem na cidade por causa da especulação imobiliária, possibilita levar mais serviços e qualidade à população, contribuindo assim para diminuir a segregação sócio-espacial.

A observação das duas imagens digitais, Landsat 1997 e 2000, (Fig. 4), apesar de um espaço de tempo muito pequeno, entre as duas imagens, seu recorte contribuiu para perceber as mudanças urbanoespaciais na cidade. Os vetores de expansão e disseminação urbana foram confirmados na análise. Se levarmos em conta variáveis, como a infra-estrutura de prestação de serviços que a cidade oferece, como o Porto Seco; Projeto Sivam; sede da Universidade Estadual de Goiás e um parque industrial já consolidado Distrito Agroindustrial de Anápolis- DAIA, bem como um comércio atacadista próspero apoiado em incentivos fiscais, e o que ela efetivamente poderia oferecer no futuro, como, aeroporto Cargueiro Comercial e tronco ferroviário das linhas Norte Sul, representam fatores de atração populacional. Ademais, sua localização geográfica, pode ser considerada também elemento de peso, principalmente porque ela se encontra entre dois centros metropolitanos saturados: Goiânia e Brasília.

Neste sentido, o crescimento urbano na cidade parece dentro dos padrões aceitáveis. Contudo, nos chama a atenção porque a expansão urbana ocorre de forma não controlada pelo Estado, sob o domínio dos agentes imobiliários, que no decorrer do tempo criam cada vez mais demandas sociais para os entes

\footnotetext{
${ }^{1}$ Veja ilustração dos trevos da cidade de Anápolis: saída para Goiânia, Brasília e Corumbá-mapa 4
} 
locais, sem a contrapartida do setor privado, inviabilizando cada vez mais um projeto de qualidade de vida local sustentado.

No mapa abaixo, Fig. 5 fizemos um esforço de apresentar uma modelização territorial para a análise espacial da cidade onde caracterizamos os principais equipamentos urbanos, e áreas Estratégicas da cidade: DAIA, Aeroporto Municipal, a Base Aérea de Anápolis, Universidade Estadual de Goiás, Estádio Jonas Duarte, Estação Aduaneira de Anápolis, o núcleo urbano da cidade, apontando sua localização no contexto urbano de Anápolis. Evidenciamos o centro da cidade, que está visualizado na parte sentetrional da área urbana. Foram evidenciadas também as áreas de expansão urbana de 1997 colorida e 2000 sombreado de vermelho, a partir da digitalização da imagem de satélite Landsat 1997 e 2000 . Observa-se que a expansão urbana desde a ocupação no primeiro terraço à margem esquerda do Córrego das Antas, cidade antiga, propiciou a estruturação da cidade ligando com as áreas de fronteiras agrícolas, na região norte e oeste. As principais vias urbanas da cidade ligavam a estas áreas e ao mesmo tempo estruturavam as áreas de crescimento urbano da cidade. Naquela época estas cidades eram caracterizadas economicamente como zonas de produção de café, e compreendia as cidades de Ouro Verde, Nerópolis entre outros. Toda produção direcionava para a cidade onde concentravam as atividades de beneficiamento da produção bem como a comercialização dos produtos. Depois da construção de Goiânia a cidade experimenta um novo surto de expansão urbana, desta vez em direção aos trevos tanto de Goiânia ao sul do sítio urbano original e também para a saída para Brasília - região sudeste. A expansão rumo ao trevo de Goiânia foi marcado pela via estruturante da cidade representada pela BR014 que cortava a cidade no sentido sul-norte, depois na década de 60 com a implantação da Br-153também denominada Belém-Brasília, a expansão urbana o acompanhou. Há de se registrar, que a construção de Brasília resultou uma nova área de expansão urbana que persiste até hoje, dando uma nova configuração à estrutura urbana da cidade, depois é claro, de ocupar o segundo terraço da

margem direita do Córrego das Antas. A região norte da cidade ainda continua a expandir, principalmente porque acompanha a estruturação da rodovia Br153, que se encontra em fase de duplicação. Um outro fator que marcou a ocupação da região norte da cidade é que desde o primeiro momento de ocupação, ela serviu as populações operárias, e até hoje possui estas características. A ligação com o norte do estado foi fato decisivo também para a ocupação desta área por populações que migraram das cidades menores do Estado de Goiás para a cidade, uma vez que grande parte que migraram para a cidade são originárias desta área do Estado. Ao passo que na região sul, encontrase um grande espaço vazio entre o centro e as áreas periféricas, cuja explicação se deve à reserva de espaços urbanos feitos pelos agentes imobiliários da cidade, e incorporadores, que lotearam as áreas distantes e reservaram as áreas intermediárias para a especulação imobiliária, sob a permissão dos agentes públicos, promovendo uma verdadeira transferência de renda para pequenos grupos de incorporadores da cidade.

Dois fatores podem explicar porque a estruturação da cidade ocorreu na parte setentrional da área urbanizada. Primeiro está relacionado com a topografia acidentada que impediu a expansão da cidade em direção a Goiânia e para a região oeste em direção a Nerópolis. Basicamente, para estas duas áreas, pode se dizer que a área urbana se encontra no limite da expansão. Para região norte, a barreira reside na implantação da base aérea de Anápolis. Embora há expansão nesta área, acompanhando a estrutura da rodovia BR153, e está próximo do limite aceitável. Na parte sul da cidade, dois fatores, pode explicar a barreira para a expansão urbana. Primeiro a implantação de uma área específica industrial-Distrito Agroindustrial de Anápolis-DAIA, e por último a localização do Aeroporto Municipal de Anápolis, com 
possibilidade de transformação em aeroporto cargueiro em breve. As tentativas de assentamento de populações trabalhadoras próximas ao Distrito Agro-industrial da cidade contribuíram para segregar mais ainda a população mais pobre, pois o loteamento fixou-se muito distante do Distrito Agro-industrial de Anápolis - DAIA e mais distante ainda do centro da cidade, tornando um problema para a prestação de serviços com água tratada, esgoto, saúde e educação a população deste local, onerando muito o ente público, como é o caso do bairro Setor Industrial Munir Carlixto.

Restaria, portanto, à parte leste e sudeste da cidade, onde está localizada atualmente a pressão por fracionamento de áreas para assentamento, pelos agentes imobiliários. Mas afinal, há necessidade de mais lotes na cidade? Certamente não! Tendo em vista que hoje a cidade apresenta mais de 60.000 lotes vazios, sendo suficiente para atender a demanda por mais de 30 anos seguintes, levando em conta o crescimento da cidade nas taxas atuais. 


\section{Modelização territorial - Anápolis - 2000}

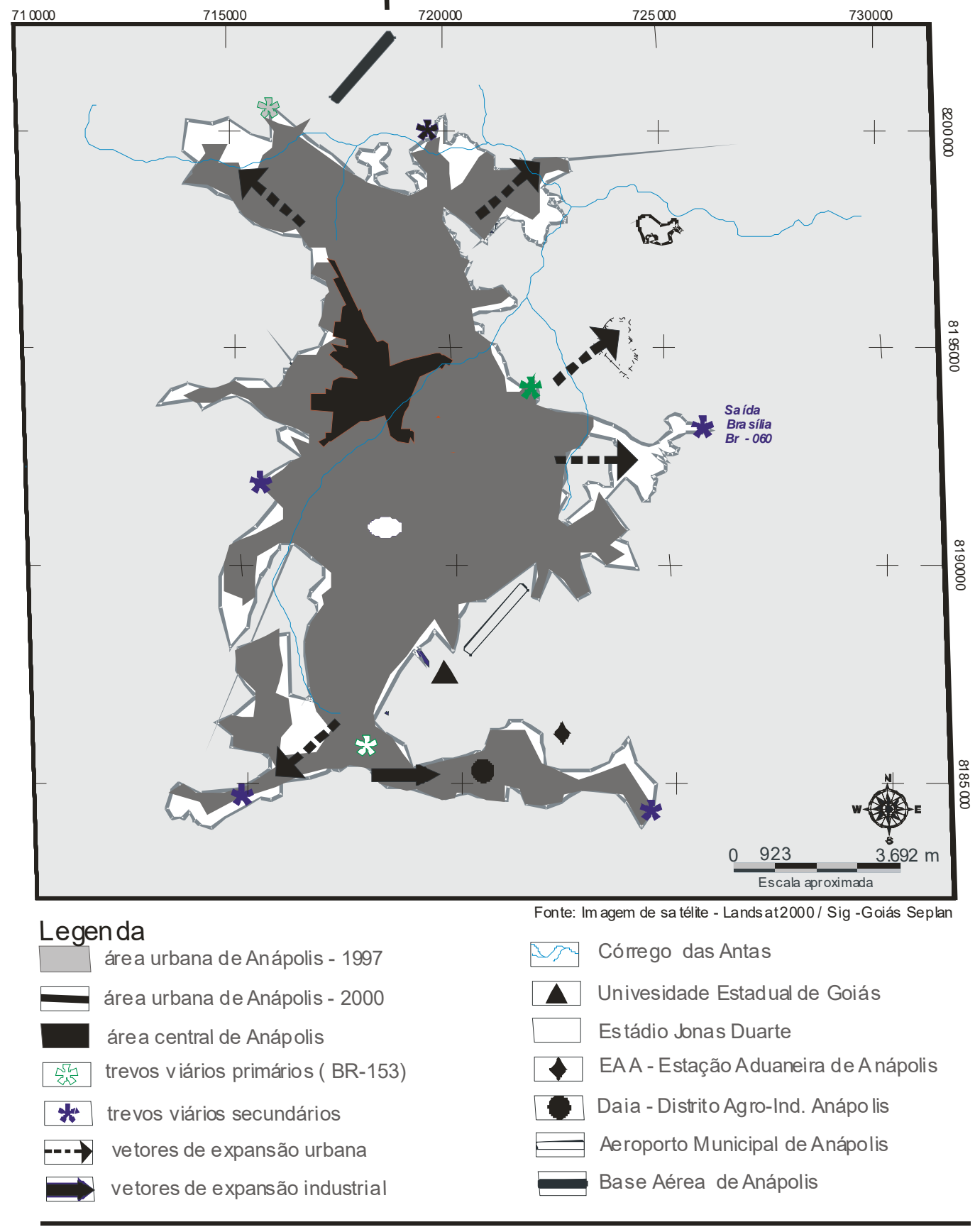

Universidade de Brasília/ Pós Gradu ação em Geografia Urbanae Regional / Mestra do em G eografia. Auno: Juvair Ferna ndes de Freitas / Orienta dor: Dr. Rafael S anżo A. Dos Anjos "A Expans ão Urbanae a S egregação Sóc io-Espac ial em A nápolis - Goás."

Considerações finais 
Após o término deste trabalho com a sobreposição das imagens Landsat digitalizadas 1997/2000, constatamos que a cidade de Anápolis apresenta um crescimento da sua malha urbana que acompanha basicamente as áreas estruturantes, correspondentes a $\mathrm{Br}-153$, em especial ao trevo de Goiânia, Brasília e saída norte. Através de trabalho de campo constatamos também que grande parte da área que se encontra como zona de expansão urbana na atualidade configuram espaços vazios, com casa dispersas, evidenciando, portanto que há uma grande especulação dos agentes imobiliários atuando nestas localidades com o aval do gestor público. $\mathrm{O}$ fato alimentador deste processo de especulação imobiliária corresponde sem dúvida ao retorno do impulso de crescimento demográfico ocorrido na cidade a partir da década de 1980, que se intensificou na década de 1990, configurando o terceiro município mais populoso do Estado, superado apenas pelos municípios de Goiânia e Aparecida de Goiânia.

Tendo a cidade, experimentado esse vulto de crescimento, constatado pelas imagens digitalizadas, num período tão curto de tempo, sugerimos, portanto para o gestor público maior empenho no controle do uso solo urbano, proibindo efetivamente a regularização de novos loteamentos até que os já existentes possam efetivamente ser ocupados. A taxação intensiva dos lotes vagos, também poderia funcionar como obstáculos à criação de novos loteamentos, bem como propiciariam a ocupação dos lotes vagos, reservados para agregar valor através da reserva de estoques de lotes.

Acreditamos que somente uma tomada de decisão desta natureza poderia transformar o espaço urbano da cidade de Anápolis sustentável e com qualidade de vida à população melhorada, sem o que, correriam o risco da cidade não oferecer os serviços destinados à população com eficiência, e a custos compatíveis com a renda dos seus moradores.

\section{Referencias bibliográficas}

POLONIAL, JUSCELINO. Anápolis nos tempos da ferrovia. Anápolis:AEE, 1995.

RIBEIRO, A .C.T. \& MACHADO, D.B.P.(org) Metropolização e Rede Urbana. Ed. IPPUR/UFRJ/set.1990. 
RIBEIRO, L. C. DE QUEIROZ.(org). O Futuro das Metrópoles: Desigualdades e governabilidade. Editora Revan, Fase 2000, Rio de Janeiro.

RIBEIRO, L. C. Q. Segregação residencial e políticas públicas: análise do espaço social da cidade na gestão do território. Texto.mimiog. inédito 2003.

RODRIGUES, ARLETE MOYSÉS - MORADIA NAS CIDADES BRASILEIRAS. Ed. CONTEXTO 1988 - SÃO PAULO

ROLNIK, RAQUEL- Planejamento Urbano nos Anos 90: novas perspectivas para velhos temas. 1994. in: Ribeiro, L.C.Q. ;Santos dos, L.A. (orgs). Globalização, Fragmentação e Reforma Urbana. Rio de Janeiro. Ed. Civilização Brasileira.

ANÁPOLIS - DADOS GERAIS INFRA-ESTRUTURA FÍSICA E URBANA DEMOGRAFIA. Secretaria Municipal de Planejamento e Coordenação. 1999

VASCONCELOS. PEDRO DE ALMEIDA. Dois Séculos de Pensamento Sobre a Cidade. Ilhéus BA, Editora Editus, 1999.

VILLAÇA. F. O Espaço Intra-Urbano no Brasil. São Paulo(SP): Studio Nobel/FAPESP,1998. 